\title{
Georeferenced Cartography and Landscape: the Protection of the Monumental Olive Heritage
}

\author{
Teresa Amodio* \\ ${ }^{a}$ University of Salerno,Department of Cultural Heritage Sciences, tamodio@unisa.it \\ * Corresponding author
}

\begin{abstract}
:
This research studies the protection of the rural landscape and agri-food heritage, offering a perspective on the role and contribution of research to support land management processes and the development of local resources.

This opportunity for reflection was created by a project developed at the request of Regione Campania, in Southern Italy, aimed at preserving the inestimable source of biodiversity represented by olive varieties from the risk of genetic erosion, and at guaranteeing the production of oils with typical and diversified organoleptic qualities and properties.

Within the scope of the project, the geo-cartographic section has analyzed, surveyed, georeferenced and represented, for a selected territory, the presence of centuries-old olive trees and allowed the creation of other research sections, more specifically agronomic and legal.

The georeferencing map of the millenary olive trees typical of the territory, together with the genetic identity card of each plant, have been inserted in a publicly accessible database, through which it is possible to trace the origins and, consequently, the quality of the oil produced.
\end{abstract}

Keywords: landscape, georeferencing, monumental olive trees

\section{Introduction}

From a conceptual point of view, interest in monumental olive trees is part of a series of studies, now consolidated in international literature (Ploeg Van Der J.D, 2008; Van Huylenbroeck G. and G. Durand, 2003), which considers monumental olive trees, as well as other types of environmental resources and rural areas, as a part of the intangible heritage of humanity, closely connected with the territories to which it belongs and, therefore, not reproducible elsewhere.

The olive tree (Olea europea L.) was probably one of the first domesticated trees, more than 5500 years ago. The first olive trees selected for oil production were almost certainly derived from the wild olive tree, known as oleaster. According to recent studies, the origin of the cultivated olive tree can be located on the borders between Turkey and Syria, in the so-called "Northern Levant". From there, most likely, the olive tree then followed the migratory routes and the routes taken by civilization in the Mediterranean Basin, which led it to Magna Graecia. In confirmation of this, olive trees already of considerable size can be seen depicted in paintings found in Pompeii that have the countryside of Magna Graecia as their background. Initially, olive oil was used as an ointment for the body or for illumination, but, later on, it became a staple food for the people of those areas. Later, the domestic olive tree followed the migratory routes of the different peoples who settled in the Mediterranean basin. It is believed, in fact, that both the ancient varieties and many of the current ones are essentially derived from a cross between the oleaster and the first varieties selected by man. Over the centuries and with the progress of agronomic cultivation techniques in addition to artificial selection, an incredible number of olive varieties have been produced, each with peculiar characteristics in terms of resistance to diseases, adaptation to various pedoclimatic environments of the Mediterranean area and oil quality. In Italy, each region has its own local cultivars and many trees grow spontaneously.

In Italy the main regions committed to olive cultivation are Campania, Puglia, Calabria and Sicily but it has its ancient roots in Irpinia. Recent archaeo-botanical studies have documented the presence of the olive tree already in Roman times, nevertheless proven by vast expanses of centuries-old trees on the hills surrounding Avellino. For the Irpinia area, as well as for the entire Campania region, numerous accessions and varieties have been described, many of which have synonymy. It is essential to investigate accessions and varieties from a genetic point of view. Recent discoveries in the field of molecular biology have allowed the development of extremely informative and low cost investigation tools. Genetic biodiversity can in fact be investigated through numerous molecular markers particularly suitable for the characterization of genetic polymorphisms for the study of genetic diversity (Nazzaro, 2008). Furthermore, these markers are transferable among very similar species; this feature makes them ideal for the construction of genetic maps and "fingerprinting" (Castiglione, 2016).

On this basis, the Tuserumona research project set out to preserve the inestimable source of biodiversity represented by olive varieties and protect them from the risk of genetic 
erosion, and to guarantee the production of oils with typical and diversified organoleptic qualities and properties.

In a nutshell, the project aimed at the registration, georeferencing, molecular mapping and plant protection is based on the construction of a localization map accompanied by the genetic profiles of each individual genotype or accession under investigation.

The project was divided into several phases:

1. geo-localization of the millenary olive trees of the Irpinia area ${ }^{1}$;

2. sampling and conservation in absolute ethanol of the leaves of geo-referenced olive trees;

3. extraction of genomic DNA from the preserved leaves in order to evaluate the quality and quantity of the extracted nucleic acids, by means of electrophoresis on agarose gel and spectrophotometric analysis.

4. genetic analysis by means of a panel of molecular markers (SSR, Simple Sequence Repeat) which are highly decisive in discriminating accessions and which also allow the identification of allelic polymorphisms. Olive DNAs were subjected to molecular characterization. Molecular data are analyzed and processed using specialist software for the study of genetic biodiversity (GenAlEx, PowerMarker) ${ }^{2}$.

5. storage of DNAs extracted and classified in super freezers at a temperature of $-80^{\circ} \mathrm{C}$.

6. creation of a Territorial Information System. The results of molecular characterization and geographic data are integrated in a geographic database, which constitutes a potential territorial information system useful for various competent bodies and departments.

7. evaluation of legal protection profiles and promotional activities related to the project results.

In this project, the geo-cartographic research section has evidently contributed to the creation of a cognitive framework capable of representing the territorial endowment relating to the precious agri-food heritage connected with olive-growing vocation and with the presence of monumental olive trees.

In particular, in light of the historical, agro-economic and cultural importance of this genetic pool, the geocartographic section has deepened the analysis of the millenary olive trees that contribute to the production of different DOP (Protected Designation of Origin) olive oils. The methodological approach has been applied to the province of Avellino, an area particularly suited to quality olive growing.

The local agricultural and rural component is characterized, in fact, by the presence of monumental olive

\footnotetext{
${ }^{1}$ (Old olive trees of Ravece, Ogliarola campana, Olivella, etc.

2 To characterize the level of genetic polymorphism existing among olive varieties most common used indices, for this type of molecular investigation, are calculated on the molecular data: observed heterozygosity (Ho); expected heterozygosity (He); Polymorphism Index Content (PIC) inbreeding coefficient (f). Furthermore, a statistical analysis was carried out using Structure software, in order to estimate the degree of genetic variability for each olive tree analyzed.
}

trees, due to the peculiar pedo-climatic conditions of the region which, over the millennia, have favored the selection of numerous varieties of olive trees, which constitute a significant genetic heritage, formed from more than 1000 varieties (Marotta G., 2011).

This source of biodiversity, which represents a source of wealth and potentialities in agriculture, needs to be preserved to avoid the risk of genetic erosion and to guarantee the production of highly diversified oils with typical organoleptic properties for each cultivation area.

\section{Methodology of geo-cartographic research}

From a cartographic point of view, the research highlights some methodological aspects.

Punctual analysis of some rural evidence requires data that can only be acquired through direct surveys.

The qualitative-quantitative method is necessary in analyses of this type.

The construction of punctual databases is possible only on a small scale and not for very large territories.

Cartographic representation requires the superimposition of raster maps (land use) with thematic maps of a punctual type.

The importance of cartography lies in the possibility of carrying out context analysis with respect to the phenomenon analyzed.

Regarding geographical considerations, in methodological terms, an attempt was made to create a tool to return the results of the research, in manner that is potentially updatable and integrable, but, above all, characterized by high usability such that it can be used in the context of strategic processes for the enhancement of local resources with a view to endogenous development (Statuto D. et al., 2019).

The methodological scheme was centered on two sections: 1. a study relating to the endowment and distribution of olive production, aimed at placing the presence of the surveyed monumental olive trees in a contextualized manner. In this phase, a series of thematic maps relating to overall olive production was created.

2 . creation of a georeferenced map (geomap) ${ }^{3}$ relating to the location of monumental olive trees present in the geographical context of reference ${ }^{4}$, accompanied by additional information levels, obtained with a link to photographic and technical documentary sections (cards);

In detail, the research was carried out as follows:

\footnotetext{
${ }^{3}$ The maps were made by the Geographic Information Systems Laboratory for the Organization of the Territory (SIGOT) of the University of Salerno, the scientific director of which is the author.

${ }^{4}$ This work was made possible thanks to the availability of part of the results made available by Tuserumona research group which, as part of sampling, in order to acquire technical and molecular information material, carried out inspections in the olive growing areas.
} 
1. analysis of olive-growing vocation, representing consistency and localization of olive production;

2. identification of areas with a strong olive-growing vocation (through CUAS and the GoogleStreetView application)

3. inspections aimed at:

- $\quad$ census of specimens of old olive trees (for a total of 103 olive trees);

- $\quad$ trace acquisition for laboratory analysis;

- georeferentiation;

- photographic documentation.

4. study on the genetic biodiversity of millenary olive varieties through molecular characterization (fingerprinting- genetic imprint) through activities of:

- collection of plant material and cataloguing;

- DNA extraction;

- amplification of SSR markers;

- bioinformatics analysis.

5. implementation of the Geographic Information System by:

- georeferencing of surveyed points;

- creation of overall cartography relating to the total sampling;

- creation of cartographic excerpts (relating to sections of the areas of interest) aimed at displaying details;

- association of the detected points of the monumental olive trees surveyed and geolocated with technical information sheets (molecular analysis, height, diameter) and photographic documentation.

6. juridical-normative analysis (with reference to the legal profiles of the collective trademark and to the «disciplinary» as a qualifying element of the collective trademark).

7. promotional economic analysis (with reference to the problems and opportunities for the economic development of monumental olive trees).

\section{Application of the method to a selected territory}

The analysis model was applied to the Province of Avellino, in Southern Italy, an area with a strong olivegrowing vocation.

In this area the peculiar pedo-climatic conditions have favored the selection over the millennia of numerous varieties of olive trees, which constitute a widely varied genetic pool. In addition, the presence of age-old olive trees contributes to the production of different DOP (Protected Designation of Origin) olive oils (Cicatelli A. et al., 2016).

\footnotetext{
${ }^{5}$ La Ravece, Ogliarola campana is among the finest varieties of the area.
}

This source of biodiversity must be preserved to avoid the risk of genetic erosion and to guarantee the production of highly diversified oils with typical organoleptic properties for each cultivation area.

In light of the historical, agro-economical and cultural importance of this genetic pool, a molecular census and characterization of the millenary varieties present was necessary ${ }^{5}$.

The first phase concerned sectoral analysis, carried out through thematic maps related to the texture and the localization of the olive-growing production area that is the object of study.

It is interesting to note that in 195 municipalities (35.4\%) of the region the percentage of olive UAA on the total UAA exceeds $15 \%$ and that this value in 43 other municipalities, almost the whole province of Salerno, is higher than $50 \%$ (Fig. 1).

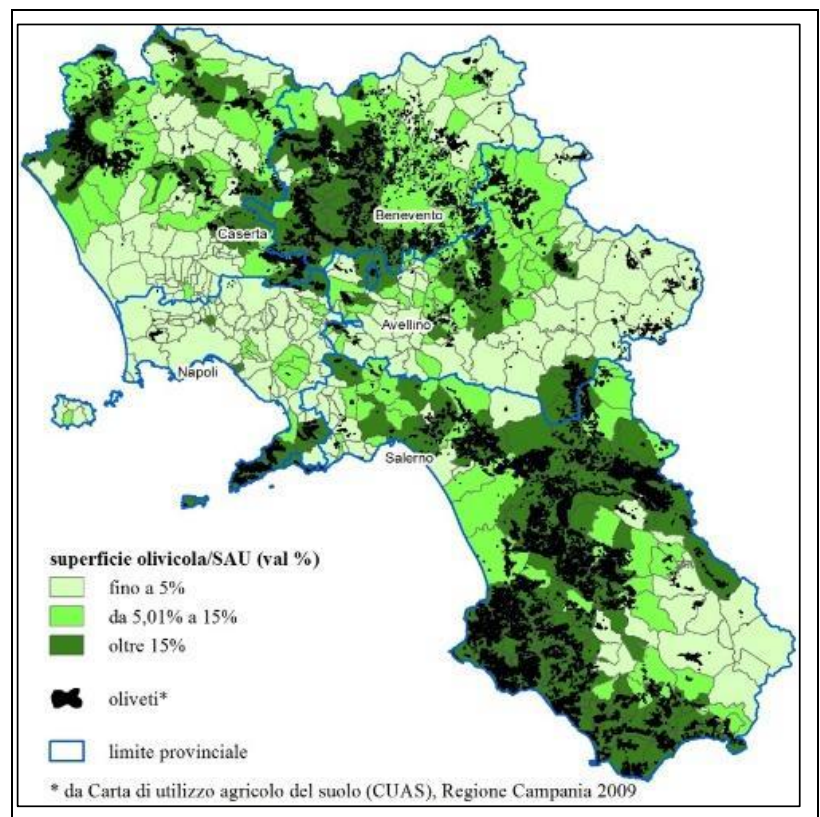

Figure 1 Olive growing in Campania (elaborations on Istat data, 2020).

From the data analysis, it emerged that, in general, with respect to the national olive-growing panorama, Campania with 72.623 hectares and an incidence equal to $6.1 \%$ of the national quota, is classed fifth in the ranking of the regions that allocate agricultural areas for olive cultivation ${ }^{6}$. Although the overall regional olive-growing sector recorded a decrease in the number of companies, it was possible to highlight an endurance of utilized agricultural area (UAA) for olives $(72.623,30$ hectares) which in 2020 appears to be in slight decline compared to the value reported in 2010. In reality, if compared with the data of previous decades, it is in substantial growth, which denotes

\footnotetext{
${ }^{6}$ Puglia, with $31.9 \%$ of the national olive-growing area, is in first place, followed by Calabria (16.3\%), Sicily (13.4\%) and Tuscany (8.2\%), Istat 2010.
} 
an encouraging situation for the survival of the supply chain ${ }^{7}$.

The regional area cultivated with olives, which with $549,270.5$ hectares represents a total of about $13.2 \%$ of the regional UAA, is mainly located in the province of Salerno, where, with $22 \%$ of the regional olive UAA $(42,469.57$ hectares) the highest levels are registered. It is followed by that of Benevento, the province where the olive UAA represents $11.11 \%$ of the regional value, and that of Avellino, where the UAA, totaling 7.562,02 hectares in 2010, has grown by $1.5 \%$ compared to 2000 .

Excluding the increase of UAA recorded in the province of Benevento $(0.6 \%)$, the province of Avellino is the only area of the region in which there has been an increase in the olive UAA, testifying to the preference given to this crop with respect to the possibility of opting for other production systems.

It is of interest to note that in 195 council areas $(35.4 \%)$ of the region, the UAA occupied by olive cultivation is over $15 \%$, and in another 43 council areas, almost all of which are located in the province of Salerno, that figure exceeds $50 \%$. The council area with the highest percentage of UAA dedicated to olives is Bellosguardo with a value of $91 \%$ (Fig 1)

The interpretation of the statistical data is confirmed by the contextual reading of the information relating to the presence and distribution of olive groves, which have been acquired from the Land Use Map, at 50.000, created by the Campania region (2009) and overlapped, in the final cartographic representation; with a map clearly showing the strong olive-growing productive vocation of Salerno and the areas between the provinces of Avellino and Benevento.

With reference to the creation of the georeferenced map, it was initially considered necessary to start with the interception of the areas characterized by the presence of olive groves. To this end, it was useful to start with the acquisition, selection and observation of satellite and orthophoto images in order to identify the sections of territories in which stretches of olive-growing areas with a traditional system were found (Fig. 2).

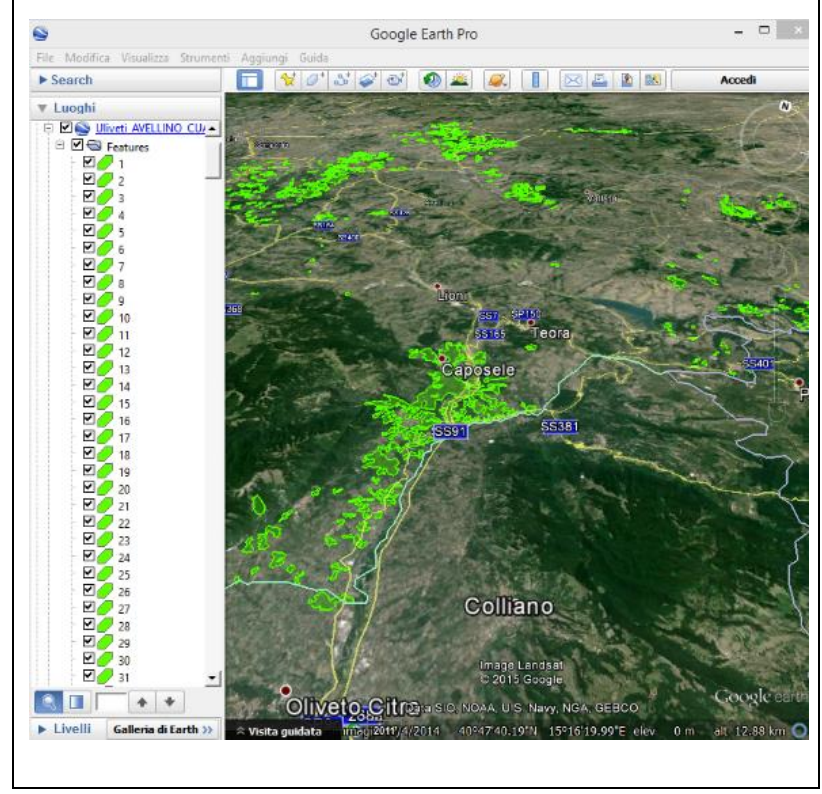

Figure 2 Localization of olive groves

The study was carried out mainly with the help of the Agricultural Land Use Charter of the Regione Campania (CUAS), from which the information level relating to the presence of olive groves was extracted.

Interpretation of the obtained information, appropriately treated through the support of GIS tools ${ }^{8}$, allowed us to identify the areas with the highest concentration of olive production (Shaaban M. et al., 2021).

The areas of interest thus identified were exported to a specific geographic data visualization tool known as Google Earth (Fig.3).

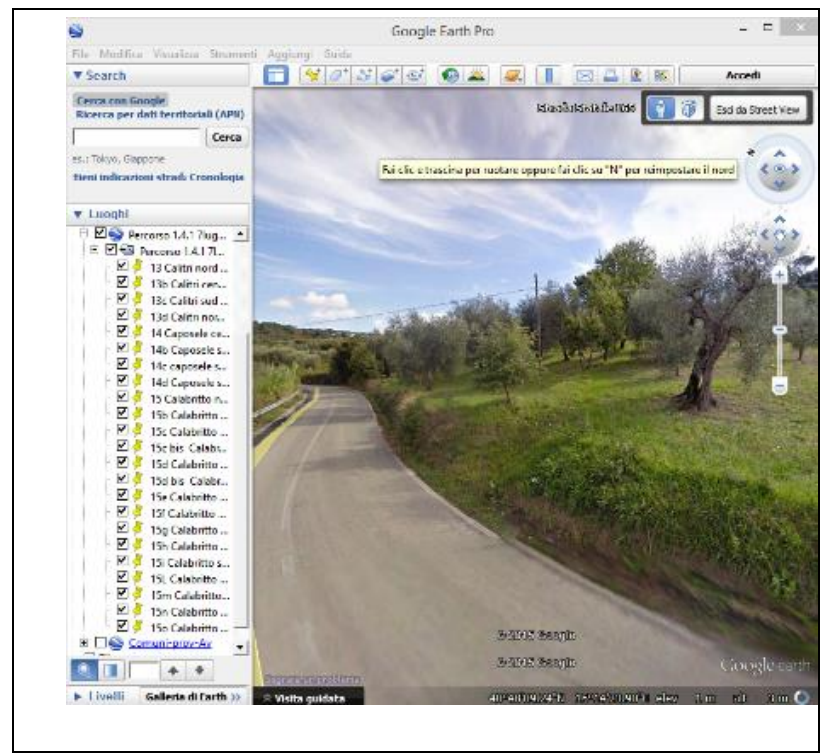

Figure 3 Google Earth's Street view

\footnotetext{
7 The data relating to the V and VII General Census of Agriculture, Istat, 2000-2010, were provided by the Statistical Office of Regione Campania.
}

${ }^{8}$ Software ESRI. 
In order to deepen investigation of the selected olivegrowing areas, a further phase of visualization and interpretation of satellite photos from the Google program was carried out. This activity allowed us, in the first instance, to identify the plantations with irregular rows and, subsequently, through the StreetView vision of the program itself, to verify the presence of geographical characteristics compatible with irregular olive cultivation, with large shrubs and, therefore, with a traditional system (Fig.4).

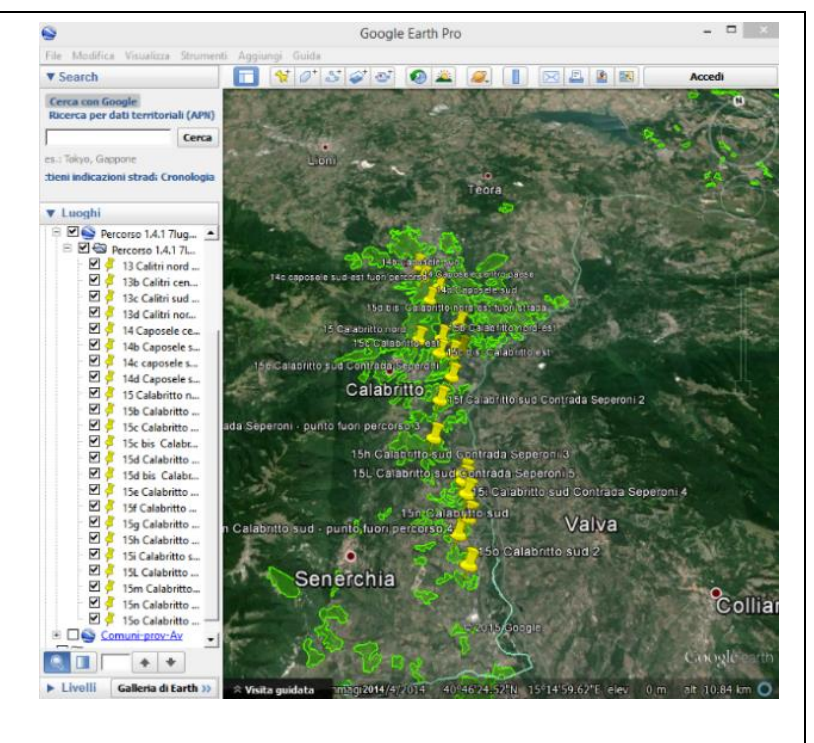

Figure 4 Selection of the points to carry out the inspections for the sampling and the photographic campaign of the specimens of monumental olive trees.

The conclusion of this phase allowed us to obtain general indications for the organization and implementation of the inspections. In particular, the choice of the paths to be followed, the sequentiality of the surveys to be carried out as well as the exact identification of the points to be surveyed were facilitated.

The next phase involved the use of a different software (MapSource by Garmin Ltd.) chosen to transform the files of the points selected with Google Earth into the most suitable format for mobile use, with portable georeferencing devices (Fig. 5).

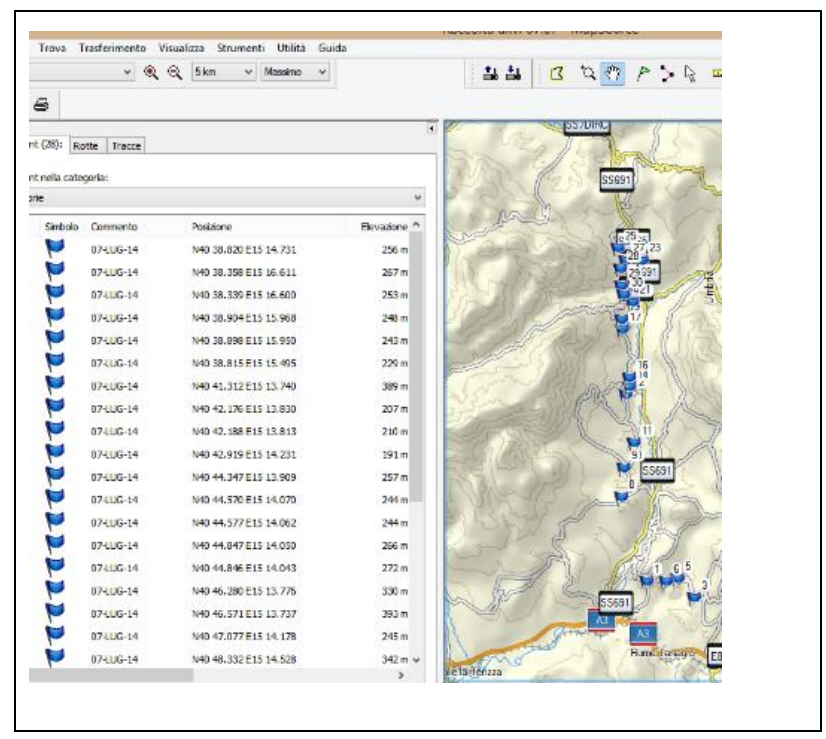

Figure 5 MapSource Framework with geographic coordinates and description of the selected inspection points.

Upon completion of the inspections, as well as of the processes of sample monitoring and reviewing, the data were processed with applications from the ESRI ArcGi suite, including ArcMap and ArcCatalog (Fig. 6).

It was therefore possible to proceed, more specifically, with the reorganization, classification and representation of the data collected on an orthographic basis ${ }^{9}$. The mobile georeferencing device provided several files in GPX format, one for each observation day. The first operation to be carried out was the reorganization of the data and the verification of the correct classification of each point (Berbel J. et al., 2018).

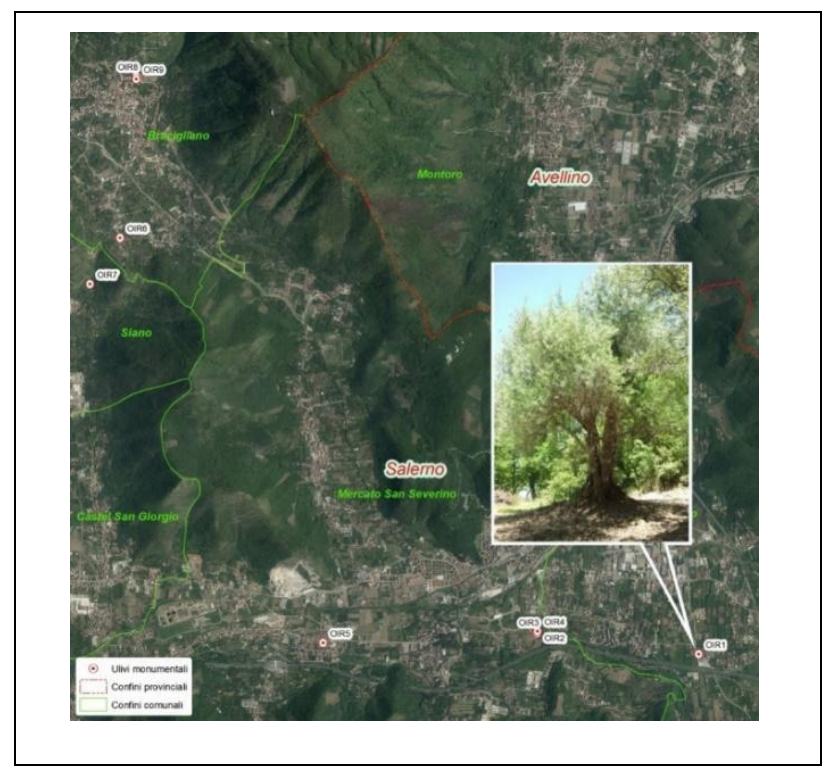

Figure 6 Example of photo display of the monumental olive tree.

9 Source of the cartographic base: Ortofoto Campania region
2011 - Orthophotos acquired in 2011, scale $1: 10,000$ in color of the AGEA 2008 flight and orthophotos, at the same scale, in 2011. 
This procedure was extremely important as it allowed to convert and implement, with high precision, the information collected during the missions as well as to guarantee their correct conversion into Shapefile format, compatible with the ArcGis suite.

The visual reorganization of the information acquired and processed in the database, was made more usable by associating the information from laboratory tests and photos with the detected points of the identified monumental olive trees (Fig. 7).

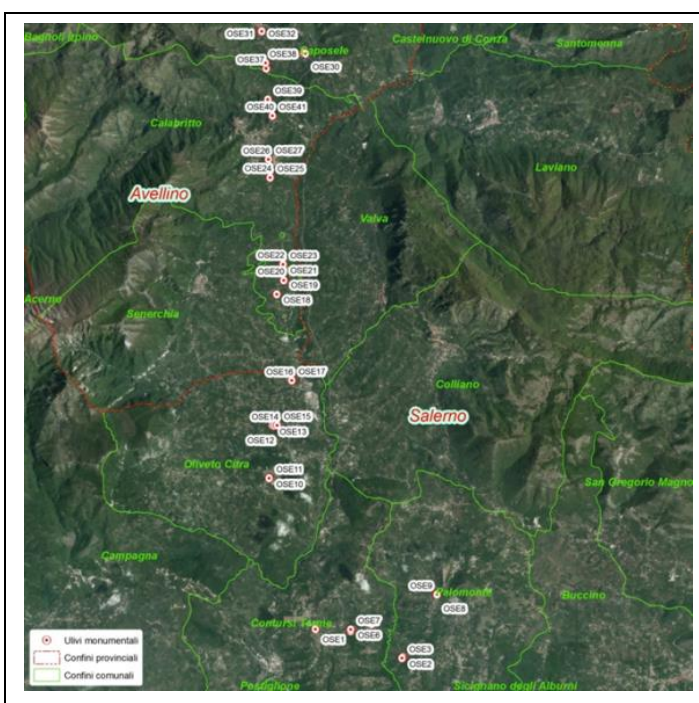

Figure 7 Overall sampling (Orthophotos of the Campania region 2011).

Finally, the used information systems allowed us to create various maps, one of which is an overall view relating to the total sampling, and cartographic extracts relating to sections of the areas of interest that can be used for detailed viewing.

\section{Conclusions}

A part of the agricultural economy of the Campania region, home of the Mediterranean diet, is based on the production of olive oil.

The olive-growing sector represents an important segment in the regional economy with a production area of 70.000 ha, with a turnover of around 200 million euros. Campania has 5 DOP oils and 13 typical varieties (including Ogliarola and Ravece in the province of Avellino), to which over 60 minor varieties can be added.

In order to protect producers and consumers the current legislation imposes the extension of the crime of counterfeiting geographical indications to those who provide false information on the origin of the oil on labels. The molecular characterization of the olive germplasm, in particular of the Irpinia area, and the establishment of a geographical database represent a valid tool for the protection of the extremely rich and diversified Campania varietal heritage.
A georeferencing map of the millenary olive trees typical of the Avellino area was created in addition to the SSR molecular typing of each olive tree analyzed. The data have been entered into a database available for public use (Wang, Y. and G. Ruhe, 2007).

The project has allowed the establishment of a germplasm bank and a register of the millenary olive trees in the selected area, which can be subsequently implemented with a census of all the oldest olive trees in the region (Torre et al. 2020).

In recent years, ancient monumental olive trees have become the object of a flourishing illegal trade due to which they are uprooted from their native lands and then end up in private gardens.

\section{References}

Agnoletti M. (a cura di) (2010). Paesaggi rurali storici, verso un catalogo, Ministero dell'Agricoltura, Bari: Laterza.

Arcidiacono A. (2020). Ecosystem Services and Green Infrastructure: Perspectives from Spatial Planning in Italy. London: Routledge.

Barberis C. (a cura di) (2009). La rivincita delle campagne, GIS-based Analysis of Temporal Evolution of Rural Landscape: A Case Study in Southern Italy. Roma: Donzelli.

Berbel J., Bournaris T., M. Basil and N. Matsatsinis, Viaggi D. (2018). Multicriteria Analysis in Agriculture: Current Trends and Recent Applications. London: Springer.

Castiglione S. (eds) (2016). Tutela e conservazione degli ulivi monumentali della provincia di Avellino Profili agronomici, giuridici e promozionali. Napoli: Edizioni Scientifiche Italiane.

Cicatelli A., Tancredi F., De Feis I. and Castiglione S. (2013). Oil composition and genetic biodiversity of ancient and new olive (Olea europea L.) varieties and accessions of southern Italy. Plant Science, 210: 82-92.

Marotta G. (eds) (2011). Nuovi modelli di agricoltura e creazione di valore. Le risorse immateriali nella governance del valore nei sistemi locali campani. Milano: Franco Angeli.

Nazzaro C. (2008). Sviluppo rurale, multifunzionalità e diversificazione in agricoltura. Milano: Franco Angeli.

Ploeg Van Der J.D. (2008). The new Peasantries: Struggles for Autonomy and Sustainability in an Era of Empire and Globalization. London: Sterling, Earthscan. Shaaban M., Schwartz C., Macpherson J. and A. Piorr. (2021). A Conceptual Model Framework for Mapping, Analyzing and Managing Supply Demand Mismatches of Ecosystem Services in Agricultural Landscapes, Land, 10(2):131. https://doi.org/10.3390/land10020131

Statuto D., Cillis G. and P. Picuno. (2019). GIS-based Analysis of Temporal Evolution of Rural Landscape: A Case Study in Southern Italy. Natural Resources Research, 28, 1-75. 
Torre A., Corsi S., Steiner M., Wallet F. and H. Westlund (2020). Smart Development for Rural Areas. London: Routledge.

Van Huylenbroeck G. and G. Durand (eds) (2003). Multifunctional Agriculture. A new Paradigm for European Agriculture and Rural Development. Burlington: Ashgate.

Wang, Y. and G. Ruhe (2007). The Cognitive Process of Decision Making. International Journal of Cognitive Informatics and Natural Intelligence, 1(2), 73-85. 